\title{
[EN-A-17] AcListant with Continuous Learning: Speech Recognition in Air Traffic Control
} (EIWAC 2019)

\author{
${ }^{+}$J. Rataj*, H. Helmke*, O. Ohneiser* \\ * Institute of Flight Guidance, \\ German Aerospace Center (DLR) \\ Lilienthalplatz 7, 38108 Braunschweig, Germany \\ [juergen.rataj | hartmut.helmke | oliver.ohneiser]@DLR.de
}

\begin{abstract}
Increasing air traffic creates many challenges for ATM. A general answer to these challenges is to increase automation. However, communication between air traffic controllers (ATCos) and pilots is widely analog and far away from digital ATM components. As communication content is important for the ATM system, commands are entered manually by the ATCo, to enable the ATM system to react to the communication. However, the disadvantage is an additional workload of ATCos. To avoid this effort automatic speech recognition (ASR) can automatically analyze the communication and extract the content of commands. To achieve low failure rates, DLR together with Saarland University invented the AcListant ${ }^{\circledR}$ system, the first assistant based speech recognition (ABSR).

AcListant ${ }^{\circledR}$ validation trials reveal also shortcomings, like problems with the costly adaptations of the recognizer to specific environments. SESAR 2020 Exploratory Research funded project MALORCA developed machine learning algorithms to automatically adapt ABSR to different airports. SESAR Industrial Research funded solution PJ 16-04 developed an ontology for ATC command transcription to enable reuse of expensive manually transcribed ATC communication. Finally, results and experiences are used in SESAR Wave-2 Solutions 96 and 97.
\end{abstract}

This paper presents the evolution from AcListant ${ }^{\circledR}$ via MALORCA, PJ.16-04 to Wave-2 Solutions 96 and 97.

Keywords: Automatic Speech Recognition, Assistant Based Speech Recognition, Machine Learning, AcListant ${ }^{\circledR}$, MALORCA, PJ.16-04, Ontology 